\title{
Governação pública e a inteligência estratégica na inovação do serviço público
}

\author{
Public Governance and Strategic Intelligence Innovation in the Public Service
}

Gobernanza Pública e Inteligencia Estratégica de Innovación en el Servicio Público

JacobMassuanganhe*

\section{Resumo}

O Mundo actual nos coloca em permanentes desafios de fazer mais e melhor. Esta tendência pela excelência decorre, por um lado, da imagem institucional, e por outro, em busca de melhor posicionamento nos segmentos em que estejamos a operar. O conceito de governação, tratando-se de um conceito social e humano, não tem ainda como vários outros conceitos sociais, uma definição geral e aceite por todos os investigadores ou peritos na área. A governação pública fixa um conjunto de princípios orientadores da boa acção e actuação dos administradores e servidores públicos em homenagem ao fim último do Estado: $a$ satisfação plena e contínua das necessidades da colectividade. Implica isto que no equacionamento das políticas públicas, há que ter em conta a metodologia da contra-inteligência com a aplicação das técnicas e abordagens para análise efi- ciente e realista dos problemas de alta complexidade e para maior eficácia da acção governamental.

Palavras-chave: Governação pública. Governação estratégica. Reforma da governação.

\section{Introdução}

A melhoria da governação é um dos fundamentais requisitos para o crescimento e o desenvolvimento. São evidentes, em todas as esferas da vida, quer no âmbito dos Poderes do Estado, quer da Sociedade, múl-

\footnotetext{
Doutorado em Políticas Públicas, Governação e Desenvolvimento Local; Pós-Doutorando em Direito na Universidade Nova de Lisboa. Coordenador de Mestrado e Pós-Graduação - Universidade Agostinho Neto. Angola. Centro de Excelência - Universidade Agostinho Neto. E-mail: jacob.massuanganhe@ gmail.com.
}

Recebido em 17/11/2014 - Aprovado em 25/03/2015 http://dx.doi.org/10.5335/hdtv.15n.1.5275 
tiplas iniciativas para o aperfeiçoamento da infraestrutura institucional, de forma a proporcionar uma nova dinâmica ao processo da governação, fundado na ampla capacidade de dar resposta aos desafios e às necessidades da colectividade. Isso quer dizer, que a governação é um conceito complexo e multifacetado que varia de organismo para organismo, de investigador para investigador, de época para época e de ciência para ciência. Numa outra perspectiva, que não fosse necessariamente administrativa, a governação, por exemplo, em relações internacionais ou outra ciência ou ramo, seria diferentemente estudada e definida. A governação surge como forma de assegurar uma maior coesão e interacção entre o Estado e a Sociedade, com aplicação de medidas e processos políticos decorrentes da aç̧ão governamental. Hoje, a dinâmica das relações sociais passou a reflectir o maior grau de liberdade das pessoas para tomar decisões sobre o seu futuro e formular a sua visão crítica sobre as novas necessidades, na perspectiva da consolidação de uma sociedade democrática e pluralista.

A governação aparece nesses termos como alavanca para a enraização e a plenitude das instituições políticas e sociais, que possibilitam a acção dos órgãos do Estado, incumbidos de implementar, acompanhar e avaliar o grau de prossecução quer das políticas públicas, dos programas e projectos, quer dos postulados inerentes à garantia dos direitos da cidadania e da democracia. Essa concepção mudou radicalmente com o papel dos movimentos políticos a partir dos anos 1900. A governação passa a ser determinante para o processo de desenvolvimento, uni- dade nacional, conquista da paz e segurança, bem como para o restabelecimento dos poderes e serviços do Estado. Assim cabe ao Estado, a importante tarefa de incentivar o fluxo de informação, de modo que a sociedade se sinta parte do processo da governação. Os avanços registrados no domínio das teorias de boa governação incentivam a práticas cada vez mais enraizados na participação e na inclusão dos actores no processo de tomada de decisão, na busca da transparência e das boas práticas nos domínios da economia e da gestão dos recursos públicos.

\section{Perspectivas da Governação}

A Governação é a ciência que estuda as relações do poder político, administrativo, gerencial e acção dos entes públicos na sociedade. O PNUD peca ao conceituar segundo LEFTWICH (citado por Pedro Pereira Lopes $(2009)^{1}$ por idealizar a democracia como a base institucional e política para a boa governação, no sentido em que declara que a democracia solidifica e torna-se sustentável por si só. Para o conceito do PNUD,

[...] a boa governação é sinónima de formas efectivas democráticas de governação. A promoção da igualdade, a tolerância, a mobilização dos recursos para o desenvolvimento do país é alguns dos atributos desta democracia. Num estado de boa governação, os sistemas são participativos, o que implica que todos membros das instituições governativas tem voz para a tomada de decisão, esta é o fundamento da legitimidade do sistema democrático (grifo do autor). 


\section{Governação Tradicional}

A Governação Tradicional se equaciona nos postulados da governação natural. É a governação exercida no domínio fora do Estado, pelas instituições e organizações comunitárias ou adstritas no seio da sociedade. Atende ao facto de que a governação tradicional ser anterior ao Estado, pelo que se rege por mecanismos do poder natural, assentes nos postulados consuetudinários, onde prevalece a crença, os hábitos e os costumes das sociedades. Aspecto importante a considerar é que a governação tradicional não faz parte dos mecanismos administrativos de dominação ou de exercício do poder, entanto, participam no processo de governação a atender a sua influência no seio da sociedade ou comunidade. A legitimidade é um aspecto fundamental quando olhamos para os mecanismos de governação tradicional.

\section{Governação Política}

A governação política na sua essência acaba sendo a mais dominante, em decorrência da acção político-partidária. Sob a óptica da ciência política, a governação política está associada a gestão política nos processos governativos. Trata-se de uma tendência para se recorrer cada vez mais à autogestão nos campos social, económico e político, e a uma nova composição de formas de gestão daí decorrentes. Com a abertura do multipartidarismo, a governação política renasce com a orientação da separação entre acção partidária e acção governamental. A acção política passa a ser equacionada numa perspectiva da voluntariedade (escolha por filiação partidária), e a acção governamental assume a supremacia de agir em nome do Estado, satisfeitas as condições de admissibilidade e aceitabilidade da sociedade. A Governação política permite combinar processos políticos e sistemas com a acção pública administrativa (mais institucional e organizacional), mas também com o fomento de uma cultura de emancipação cultural e política para os indivíduos e para os territórios.

\section{Governação Corporativa}

A Governação corporativa é vista como tendo um âmbito mais restrito, e foca a atenção mais discretamente sobre um nível designado de governo em particular. Isso é diferente das concepções mais amplas de "Governação pública", acima descrita. Governação corporativa (corporate governance) é uma área de estudo com múltiplas abordagens. Existem muitas definições para o termo Governação Corporativa. Dentre vários, posição comum advoga que é um sistema pelo qual as organizações são dirigidas e controladas (monitoradas), envolvendo todos interessados. A governação corporativa ou governo das sociedades ${ }^{2}$ é o conjunto de processos, costumes, políticas, leis, regulamentos e instituições que regulam a maneira como uma empresa é dirigida, administrada ou controlada. Assim, a governação corporativa é composta pelo conjunto de mecanismos e de regras pelas quais se estabelecem formas de controlo da gestão das sociedades, e 
onde se incluem instrumentos para monitoria e possibilidade de responsabilização dos gestores pelas suas decisões (ou actos de gestão). Visa diminuir os eventuais problemas que podem surgir na relação entre as partes interessadas e, consequentemente, diminuir o risco de custos da agência. Corporate Governance é um espaço aberto para criar interação entre os diferentes actores internos e externos, em prol de um objectivo comum. Partindo-se dessa teoria organizativa pretende-se identificar o interesse social como a perpetuação da organização e a sua valorização como medida estratégica (capital imaterial).

\section{Governação Económica}

A Governação Económica é vista como parte da gestão governativa que cuida por um conjunto de políticas e instrumentos para dinamizar a economia e promover o desenvolvimento. A Governação económica implica o alinhamento entre o Poder Político e o Poder Económico. Trata-se de um jogo de apostas, mas que afecta o andamento da economia real. A Governação Económica é vista como uma combinação de técnicas de administração, economia institucional e gestão de serviços público, orientadas para a racionalização de instrumentos de políticas que tenham em vista o aumento da produtividade e efectividade na administração pública, garantindo mais investimentos e uma maior valorização dos recursos de modo a que sejam mais produtivos e reprodutivos.

A Governação Económica se assenta em medidas mais rigorosa das políticas económica e orçamental orientadas para a esta- bilidade e Crescimento quer através da criação de novos instrumentos para fazer face aos desequilíbrios macroeconómicos. É a área que se concentra pelas políticas económicas, regulação e instrumentos de política económica. Analisa as tendências e estuda reformas com vista a melhorar o ambiente de negócios, a racionalização da despesa pública e o comportamento da balança comercial. Procura estudar os choques externos, os riscos inerentes à volatilidade da economia através da análise dos diversos indicadores do desenvolvimento humano, incluindo a pobreza, a saúde e a educação, etc.

\section{Governacão Pública}

Governação pública se refere a actividade governativa exercida no Setor Público. Ocupa um lugar central neste esquema de conceitos relacionados com a governação. Ele foca a Governação no domínio público em geral, incluindo, mas não limitado a, função e operação do governo. Isso confirma que a Governação no sector público abrange processos mais amplos que se estendem para além das estruturas formais de governo. A Governação Pública surge como avanço das teorias administrativas que vem se consolidado desde os anos 70. Essa nova perspectiva de Governação pública reconhece um Estado Plural, onde vários atores interdependentes contribuem para a prestação de serviços públicos e um Estado Pluralista, onde vários processos informam o sistema de formulação de políticas. Como consequência destas duas formas de pluralidade, seu foco está muito acima dos relacionamentos inter-organizacionais e da Governação de 
processos, gerando eficácia e resultado nos serviços públicos (OSBORNE, 2006 apud EDWARDS, 2012).

Governação pública, portanto, abrange não só Governação no que se refere às instituições e aos negócios do governo, mas também o envolvimento do governo com os sectores não governamentais no processo de Governação. A partir desta perspectiva, a noção geral de "Governação" (e "governar") é convencionalmente associada com 'os processos que criam as condições para estabelecimento de regras ordenadas e acções colectivas na esfera pública. A governação é baseada em princípios são caracteristicamente vistos como mais flexíveis e menos prescritivos do que baseadas em regras, permitindo assim mais espaço para personalização nas organizações "(EDWARDS, 2012). A governança pública envolve os princípios da transparência, equidade e responsabilidade social, sustentado nos princípios éticos e envolve toda a sociedade (governo, organizações privadas e sociedade). A Governação pública é o sistema que assegura às partes interessadas pertinentes, o governo estratégico das organizações públicas e o efetivo monitoramento da alta administração. A relação entre a coisa pública e a gestão se dá por meio de práticas de medição, tais como: auditorias independentes; unidades de avaliação; unidades de controlo interno e externo; instrumentos fundamentais param o exercício do controlo.

\section{Governação Estratégica}

\section{Fundamentos de Governação Estratégica}

As mudanças estruturais e conjunturais observadas nos últimos anos, o agravamento das condições de vida e a crescente complexidade das necessidades da sociedade, associadas à incerteza e contextos adversos fora do controlo das estruturas governamentais levam a que a acção governamental seja reorientada para uma faceta estratégica, o que pressupõe o aprimoramento do modelo organizatório e funcional da maquina administrativa, capacidade de prever e antecipar, a capacidade de intervir, inovar, e a capacidade de se adequar e adaptar-se aos problemas do presente e do futuro. $\mathrm{Na}$ governação estratégica, pode-se dizer que o exercício governativo pode ser visto em diferentes perspectivas, no entanto para que se tenha bons resultados não será suficiente agir de forma tradicional. A Governação estratégica procura introduzir novas formas de conceber e actuar no exercício de funções de natureza pública ou privada. Implica agregar valor na acção através de indução dos processos, inovação e criatividade. O facto é que com a governação estratégica, o processo de administrar ou de gerir passa a ser equacionado de diferente. Valoriza-se o planeamento estratégico e uma gestão orientada para a maximização dos rácios de eficiência (impacto). A Governação estratégica vai apoiar os administradores e dirigentes públicos no equacionamento de forma inteligente as opções em termos de acção, actuação e interação, subsidiando 
com técnicas, ferramentas e informações para o processo decisório.

A estratégia somente gera valor quando executada, e não há execução efetiva sem gestão. A Governança Estratégica é uma peça fundamental para assegurar que a estratégia não se converta em um exercício de reflexão e em documentos sem aplicação prática. A Governação Estratégica é orientada por forma a que a acção governamental possa optimizar os resultados de forma eficiente. É preciso integrá-los para garantir que a alta liderança não se perca nos diversos domínios metodológicos. Além disso, em um ambiente de negócios cada vez mais volátil, o modelo de governança da estratégia precisa assegurar accountability sobre os objetivos e ações e foco na implementação com respostas rápidas e precisas. A governação estratégica incentiva o pensamento visionário no quadro da definição, da implementação e da avaliação das políticas governamentais.

No quadro da reforma governativa (realinhamento estratégico) é importante que os líderes públicos se orientem pela faceta centrada na valorização crescente da contra-inteligência. Se os funcionários não se sentem envolvidos no processo da reforma, ou seja, se as reformas não tem uma tangência explícita no que constitui de igual modo preocupação dos funcionários (progressão, promoção, melhoria das suas condições de trabalho, etc.), implica que os postulados da reforma não terão qualquer impacto. Neste caso há que antecipar os eventos futuros e procurar responder hoje (antecipabilidade). Se orienta pela identificação de soluções de impacto e com efeitos multiplicadores e como tal assume como premissa o tempo como factor crítico, pelo que a acção governamental deve ser vista na perspectiva de assegurar soluções que garantam impacto em curto prazo. Implica forte capacidade de prever o futuro - A previsibilidade.

\section{Práticas da Governação Estratégica}

A Governação Estratégica considera a unicidade dos processos de orientação da máquina administrativa e gestionária de forma sistémica. Define um conjunto de diretrizes norteadores de actuação institucional de forma coordenada onde cada um dos actores tem uma responsabilidade específica. A Governação Estratégica tem vindo a ser aplicada como mecanismo de integração das acções dos diferentes Departamentos ministeriais, bem como acção política no exercício do poder corporativo ou governamental público. Se assenta nos princípios da governação vistos numa dimensão de longo prazo: uma descentralização estratégica não poderá ter tão-somente uma orientação política, é importante equacionar os riscos associados, os custos associados, as implicações na vida das populações e tornar num processo que envolva todas sensibilidades.

Nesse sentido, no quadro da reforma da governação, a visão estratégica governativa é importante no quadro do fortalecimento dos lanços e indução de uma administração inteligente assente na valorização dos recursos e maximização do impacto das intervenções públicas. Na Governação Estratégica é importante a necessidade contínua de revisão e acompanhamento da 
execução do Planeamento Estratégico; a modernização da gestão por meio do estabelecimento de padrões de Governação na administração pública; e o aprimoramento dos mecanismos de controlo estratégico. A formulação da estratégia refere-se ao processo de escolha do curso de ação mais apropriado para a realização de metas e objetivos. A Governação Estratégica, especificamente vai se orientar o quadro de implementação das acções estratégicas (de impacto) pelo que atenção será dispensada no monitoramento, a avaliação e o aprendizado (boas praticas administrativas e de gestão).

\section{Análise Estratégica Governativa}

A Acção governativa implica implantação de um novo modelo de Governação com fundamentação estratégica, visa contribuir para uma administração e gestão pública cada vez mais actuante. A Governação Estratégica é vista como a combinação das técnicas administrativas com as práticas de gestão, orientadas para a melhoria da concepção dos programas e actuação dos administradores públicos. Na prática, procura-se implantar uma filosofia em que a acção governamental passa a ser vista em termos de peso estratégico, pois a finalidade da Gestão Estratégica é assegurar que as intervenções públicas sejam de impacto, garantindo o rácio de eficácia e eficiência - Qualidade dos resultados. Nesses termos pode-se estabelecer o critério valorativo das intervenções em quatro dimensões:
A - Alta acção Governamental com Baixo Peso Estratégico: Nesse quadrante a acção governamental é vista numa perspectiva de alta dimensão em termos de actividades, no entanto sem qualquer contrapartida ou peso estratégico. Sempre que isto acontece, implica que as aç̧ões não terão qualquer impacto.

B - Quadrante de Alta acção Governamental com Alto Peso Estratégico: Nesse quadrante, a acção governamental tem grande peso e de igual modo se assegurar uma orientação estratégica. Implica isto dizer que a intervenção pública, embora garantam impacto, isso é alcançado a custos bastante altos.

\section{C - Quadrante de Baixa acção Governa-} mental com Baixo Peso Estratégico: Nesse quadrante, a acção governamental é orientada para poucas realizações sem qualquer peso estratégico, o que pressupõe que as mesmas não têm impacto no seio da sociedade.

\section{D - Quadrante de Baixa aç̧ão Governa-} mental com Alto Peso Estratégico: Nesse quadrante, a acção governamental é orientada para poucas realizações, mas de grande valor (qualitativo). Esse é o quadrante estratégico da acção governativa, ilustrando que com poucas realizações e dado o peso estratégico o governo possibilita impacto nas suas realizações. Com base nesses parâmetros, denota-se que os serviços do Estado somente terão relevância quando maior foro o peso estratégico, que possibilitará alta relevância estratégica e baixa aplicação de recursos. 
Figura 1: Acção Estratégica Governamental

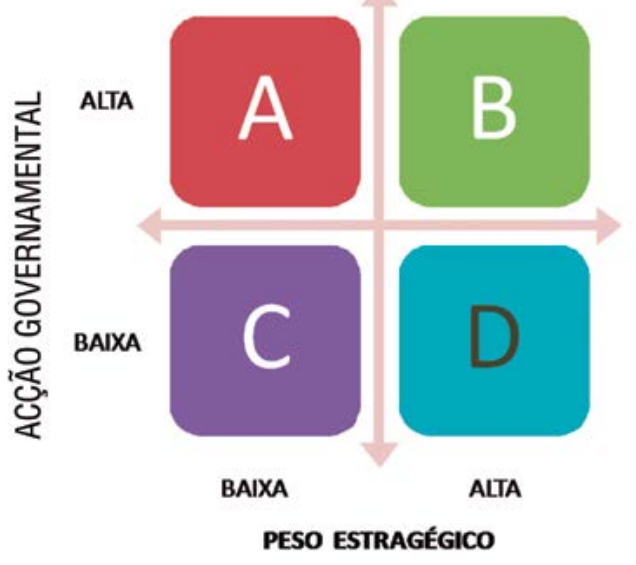

Fonte: do autor.

\section{Inteligência sistémica empreendedora}

À medida que o mundo vai evoluindo como resultado do avanço da ciência e da tecnologia, crescem os problemas associados ao presente e ao futuro. Cresce a preocupação quanto à soluções à altura da complexidade dos problemas correntes e recorrentes, emergentes e iminentes. Não obstante o avanço do conhecimento, esse tem estado aquém para fazer face aos desafios actuais e à complexidade com que problemas tendem a evoluir. Como resultado, agrava-se a incerteza quanto ao futuro existencial da humanidade. Ademais, os fenómenos tendem a evoluir exponencialmente e numa proporção acelerada como resultado da dinamicidade e das (inter)relações estabelecidas entre si, dando origem a novas configurações e dimensões cada vez mais críticas e complexas (caso das epidemias em África). Ou seja, à medida que o tempo passa os problemas tendem a se solidificar criando estruturas cada vez mais impermeáveis.
É assim que como forma de catalogação do efeito relacional e sistémico dos problemas que afligem a humanidade nasce a Inteligência Sistémica Empreendedora (ISE). A inteligência sistémica assume como premissa a necessidade da identificação de soluções efectivas para os problemas, tendo como base os fundamentos associados a esses, ou seja, para que a solução de um problema seja sustentável, essa deve ser encontrada dentro do conjunto sistémico que caracteriza a própria natureza do problema (a solução reside dentro do próprio problema). Uma segunda premissa da ISE é que assume que toda a solução em que o problema não tenha sido equacionado na sua plenitude, este tende a assumir um efeito regenerativo (ressurgir). É importante avaliar o ambiente como um todo - Nasce assim o efeito sistémico. Em terceiro plano, é preciso considerar que à medida que o tempo passa, os factores adjectivos associados aos problemas tendem a se relacionar entre si, dando origem a uma nova forma, ou seja, na física diz-se que quando se tem duas partículas em mesmo ambiente durante algum tempo, as características duma acabam influenciando a outra, criando uma única partícula - Nasce assim o efeito generativo.

\section{A Inteligência Sistémica Empreendedora}

Enquanto a Inteligência Estratégica Visionária (IEV) está preocupada com o futuro (equacionar perspectivas do futuro associadas ao presente, através da previsão ou antecipação). A IEV é vista como aç̧ão condicionante orientada para avaliar as estratégia e definir critérios de eficácia, 
é uma acção prévia que procura criar ambiente para a eficácia da estratégia (cria as condições favoráveis para a estratégia). Já a Inteligência Sistémica Empreendedora (ISE) está preocupada com o presente associado a perspectivas de longo prazo (equacionar soluções de curto prazo que seriam de longo prazo). A ISE está centrada no diagnóstico dos problemas e gerar soluções efectivas (de impacto imediato e efeitos multiplicadores). A ISE está preocupada com o presente e a acção imediata que se tomaria no futuro isto é os problemas de hoje cuja solução passaria por algum tempo. A ISE é vista como acção determinante (decorre ao longo da implementação da estratégia).

A ISE procura produzir efeito da estratégia em curto prazo (acção que produz efeitos imediatos que seriam de longo prazo). Tem a ver com o equacionamento táctico para induzir os resultados. Procura influenciar as tácticas para que possam produzir impacto, ou seja, para a criar ambiente que seja favorável para a eficiência táctica. Centra-se na acção com efeitos multiplicadores (único investimento com benefícios múltiplos). Parte do hoje para trazer soluções de impacto e efeitos futuros, isto é, soluções imediatas que, em situação normal, levariam tempo para alcançarem resultados e gerar impacto. A Inteligência Sistémica Empreendedora está preocupada com soluções de curto prazo para problemas do presente e do futuro, e procura induzir soluções efectivas para problemas complexos. Assume-se que a solução pode ser conhecida ou não conhecida, no entanto a preocupação será o tempo que essa solução irá levar para resolver o problema bem como o tempo para que se tenha a mudança, que passa a ser vista como dimensão de curto prazo. Os resultados ou reflexo da acção são vistos numa perspectiva de curto prazo. Na ISE as soluções de problemas devem ser concebidas e implementadas para produzir resultados imediatos que em condições normais estas soluções trariam benefícios em longo prazo - solução imediata - quick win (aceleração do período de maturação). Subentende-se que as soluções induzidas (impacto e retorno imediato) concorrem para a eficácia táctica e eficiência da estratégia e por conseguinte concorrem para o bem-estar (efectividade).

A ISE é uma ferramenta orientada para diagnosticar, reflectir e analisar soluções que induzem a mudança em curto prazo. Traduz os efeitos de longo prazo para uma perspectiva de curto prazo mantendo as características quanto à eficiência e efectividade (impacto e efeitos). Por exemplo, se o pinto tem um ciclo normal de 45 dias para se tornar comercializável, a ISC procura reduzir o ciclo para 10 dias, mantendo as mesmas propriedades. O ganho da ISE está assente no tempo, pelo que a satisfação está associada ao período de tempo que se leva para dar solução e ao tempo que essa solução leva para produzir efeitos. É assim que a ISR passa a ser vista como um laboratório para o diagnóstico dos problemas bem como para analise e priorização das soluções (processo decisório). 


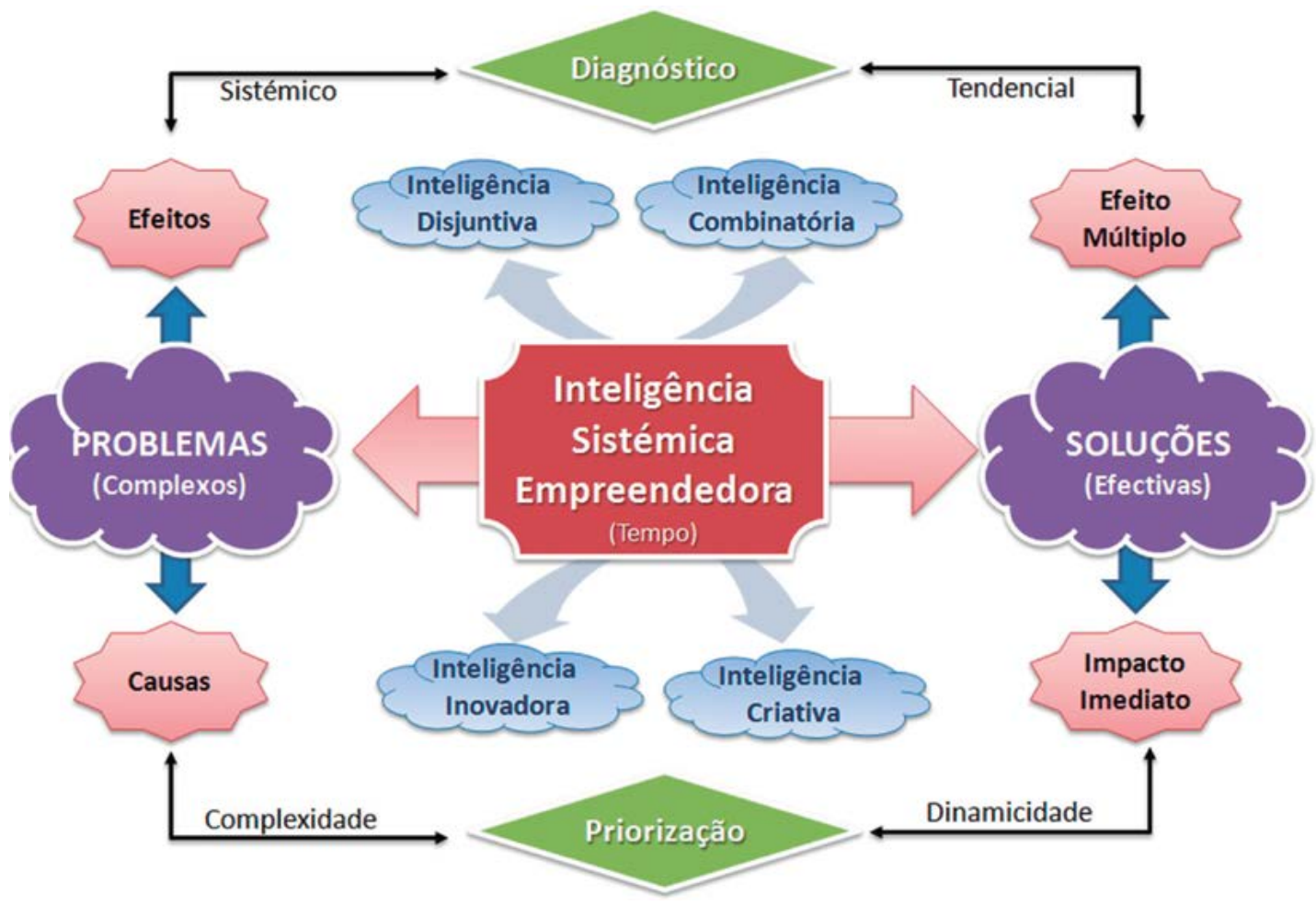

Fonte: do autor.

\section{Inteligência disjuntiva e combinatória}

na - eficiência da administração

A inteligência disjuntiva e combinatória se assenta na busca de novas soluções associadas a problemas de hoje e de amanhã com aplicação de diferentes métodos e técnicas. Centra atenção na identificação das estratégias que vão garantir alto nível de eficiência - eficiência estratégica. Implica que, da mesma forma que equacionamento o efeito sistémico do lado dos problemas, é preciso atender a essas premissas no equacionamento das soluções, pois o efeito relacional acaba criando dependências e/ou interdependências entre as partículas que passam a fazer parte dum único sistema (visão integrada). A função disjuntiva decorre da separabilidade - decompor em partícula.

Para a ISE nada está desassociado do resto, os fenómenos são a manifestação ou a reaç̧ão expressa das partes de um todo. A inteligência passa a ser vista como a capacidade conjuntiva ou disjuntiva de entender, reflectir e conceber soluções integradas para resolver situações concretas do presente e do futuro: agir de forma diferente, fazer coisas certas, no momento certo, com recurso certos e no local certo. Está preocupada com o 
reprocesso dos processos, visando o encurtamento do tempo necessário para que esses tenham sua eficácia e a melhoria da qualidade do resultado. A preocupação é a criar ou melhoria continua por meio de reprocessos. Por exemplo, um taxista para perfazer a receita de 2000k precisa de 12 horas. Este pode encurtar as rotas e conseguir a mesma receita em menos tempo e menos recursos (combustível).

Figura 3: Inteligência Disjuntiva Combinatória

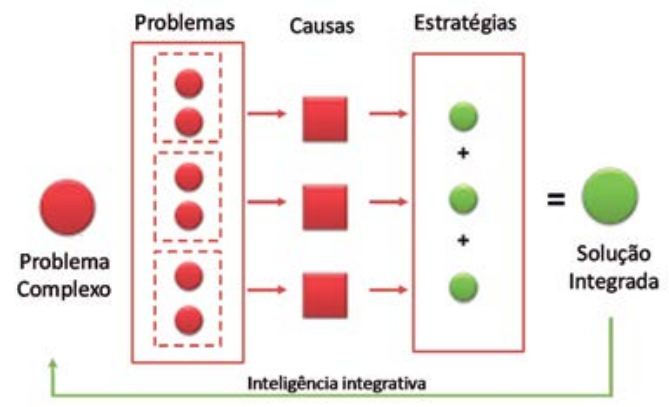

Fonte: do autor.

\section{Inteligência Existencial e Criativa - Efectividade na Governação}

A Inteligência Existencial e Criativa decorre das faculdades técnicas em busca do novo conhecimento aplicado na vivência prática bem como o aperfeiçoamento das técnicas que vão gerar maior efectividade das intervenções. Se assenta na determinação das prioridades, atendendo a dois princípios: (i) Impacto imediato (quick win); e (ii) efeito multiplicador. Enquanto a primeira centra atenção em medidas de eficiência, a segunda é orientada para os padrões de efectividade. Tanto o padrão de impacto imediato, quanto o de efeito multiplicador, embora sejam orientados para médio e longo prazo, respectivamente, procuram induzir a uma dimensão de curto prazo. O fundamento principal é induzir a mudança a partir da criatividade inovação. Na governação a inteligência inovadora contribui para o aperfeiçoamento das técnicas, orientadas para o melhor fazer, sem implicar adopção de novos modelos. Por exemplo, no planeamento público, não basta arrolar as necessidades, é preciso identificar as formas de sustentação a partir de premissas criativas (criando empresas municipais) ou inovadoras (aproveitamento de locais turísticos como fonte de receitas).

Figura 4: Inteligência Disjuntiva Combinatória

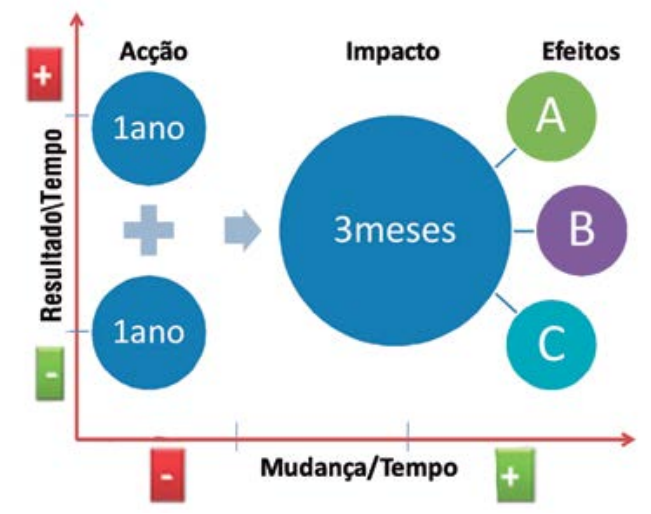

Fonte: do autor.

Garante o aumento da produtividade e contenção dos recursos o que contribuiu para métricas de desempenho superior eficiência ou impacto de curto prazo (Quick wins). A finalidade é reduzir o tempo que se leva para dar solução ao mesmo tempo em que a solução deve ser integrativa - produzir efeitos em curto prazo. Na Administração, a Inteligência Criativa é vista como ferramenta para melhor compreensão dos problemas actuais e futuro e como técnica para solucioná-los de forma simples e rápi- 
da. Neste aspecto como se a inteligência se focasse essencialmente no aperfeiçoamento e melhoramento das ideias que já existem, enquanto a criatividade centra-se em criar novas ideias. No entanto muitas vezes é possível aperfeiçoar ideias já existentes, substituindo as ideias adjacentes por novas.

\section{Inteligência estratégica visionária}

Os Líderes de sucesso não se preocupam somente com os fins, mas de igual modo, procuram prestar atenção ao ambiente envolvente como ponto de partida (acção ex-ante) e depois vêm os meios (processos), pois o sucesso da estratégia depende das condições estabelecidas para a sua eficácia e da eficiência dos processos. Se estes elementos forem mal equacionados, os resultados poderão não ser alcançados, ou se forem, poderão não na magnitude esperada. É importante notar que na inteligência estratégica visionária, não basta a estratégia (acção), mas também há que ter em conta os mecanismos para fazer face à incerteza (contra-acção), ou seja, há que atender ao efeito do risco e as medidas de mitigação. A aç̧ão serve de fundamento estratégico que assegura a direcção e guia os objectivos da organização, já a contra-acção serve de mecanismo de defesa.

Enquanto a inteligência estratégica centra-se na escolha de diferentes cenários (caminhos) para se alcançar um determinado fim, a inteligência visionária centra atenção na antecipação, e como tal, serve de instrumento de aperfeiçoamento das estratégias e de suporte às tácticas, atendendo aos riscos e incertezas - e assim, nasce a Inteligência estratégica visionária. A inteligência estraté- gica visionária é uma acção prévia, antecede a estratégia. É uma ferramenta orientada para o estabelecimento de condições, cria o ambiente para a eficácia da estratégia (enable environment). $\mathrm{O}$ processo estratégico-visionário implica uma conjugação de diferentes habilidades e técnicas, perspectiva ofensiva e por vezes defensiva, ou seja, uma estratégia deve por vezes ser equacionada tendo em conta não somente o resultado pretendido, mas também equacionar os riscos associados, de tal forma que se os riscos forem superiores que os resultados, então há que apostar na acção ex-ante (condicionantes), e se os riscos forem reduzidos, então a acção ex-post (determinantes).

A inteligência estratégica, na era moderna é vista como ferramenta fundamental para o processo de tomada de decisão de forma segura e sustentável. Implica isto que uma decisão não poderá ser boa se não tiver sido tomada com base em conhecimentos relativos a factos conhecidos e não conhecidos. Há que atender a eficácia, mas sobre tudo às implicações das decisões tomadas hoje no futuro. De acordo com Leandro Presumido Júnior (2010), a inteligência estratégica teve seus destaques nas grandes guerras mundiais, porém o marco de transformacional para os conceitos actuais, foi o triste episódio de 11 de Setembro de 2001. O acto terrorista que abalou as estruturas de segurança mundial, expondo a fragilidade dos sistemas até então utilizados, transformou as operadoras de inteligência objectivando a obtenção de dados confiáveis com maior rapidez e confiabilidade. Quando se estudou as causas das falhas ocorridas no episódio "Torres Gêmeas", uma das descobertas é que as Agen- 
cias de Inteligência haviam se tornado órgãos excessivamente burocráticos, morosos e pouco dispostos a passar por riscos.

A inteligência estratégica visionária (IEV) é uma acção prévia, antecede a estratégia. É uma ferramenta orientada para o estabelecimento de condições e/ou ambiente para a eficácia da estratégia. A função de IEV é a de corrigir erros ou desvios, prevenir cenários e gerir as contingências (riscos). Conjuga o presente e o futuro, e como tal, combina meios mais adequados orientados para um determinado fim, com técnicas de antecipação do futuro. Enquanto o estratégico centra-se nos postulados do presente e equaciona o longo prazo (futuro), o visionário centra-se nos postulados do presente com base nas projecções sobre o futuro. As duas vertentes (estratégica e visionária) exigem habilidades especulativas além das capacidades.

Figura 5: Inteligência Estratégica Visionária

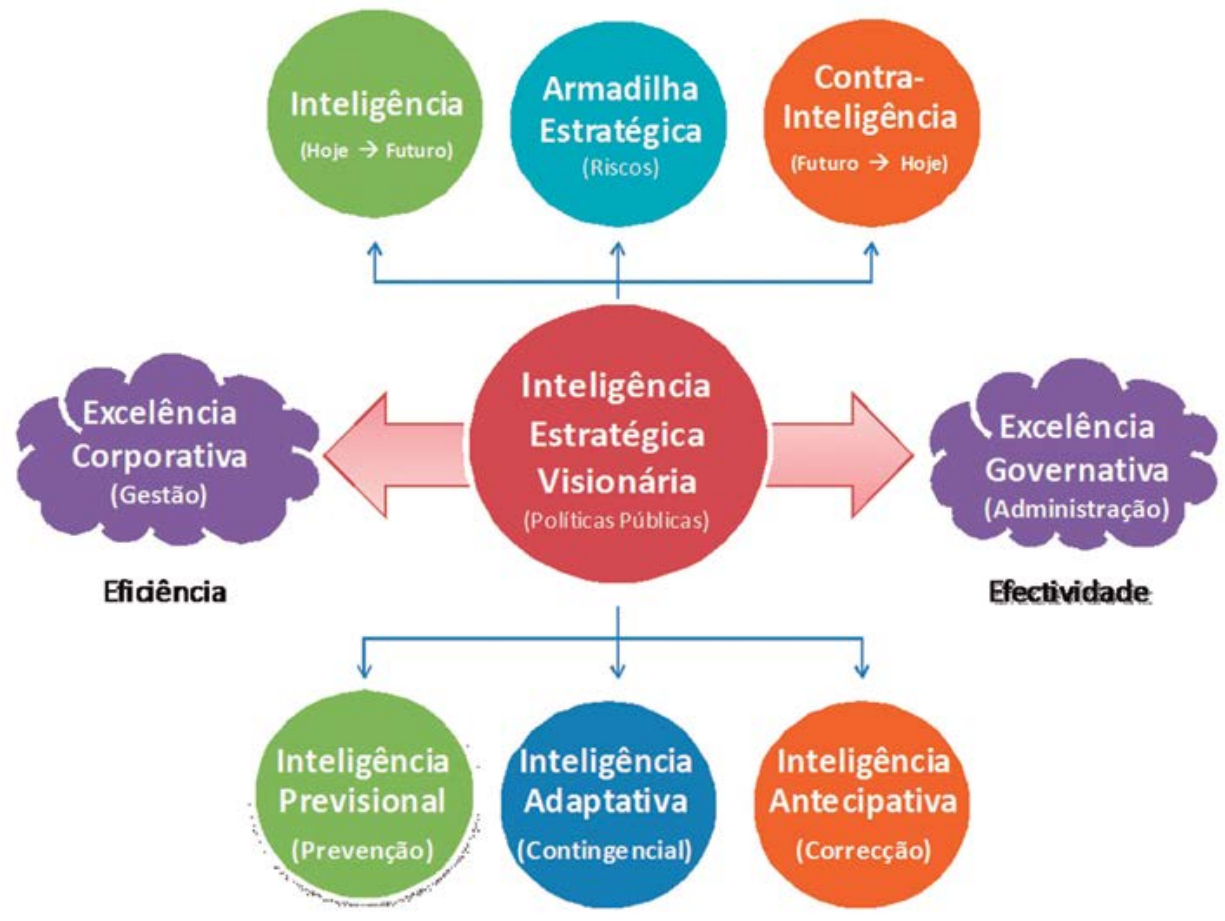

Fonte: do autor.

A inteligência estratégica visionária serve de igual modo, como instrumento de ensaio para medir a pertinência da estratégia. Trata de conjugar as peças que asseguram os resultados da estratégia em longo prazo, que vão sustentar os desafios do futuro, procurando agregar valor das acções e oportunidades correntes. Equaciona os objectivos futuros atendendo a um conjunto múltiplo de factores, traduzindo em função dessa análise a pertinência da estratégia, olhando para o futuro. Enquanto 
a estratégia centra-se na escolha de diferentes cenários (caminhos) para se alcançar um determinado fim, a inteligência estratégia visionária centra atenção no aperfeiçoamento das estratégias e serve de suporte às tácticas. A estratégia pode ser vista como via, mas também como o produto.

A estratégia é o fim associado a um produto ou estágio pretendido. Nesta perspectiva levanta-se a questão da eficácia da estratégia o que pressupõe medidas de antecipação visando à criação do ambiente necessário para a efectividade das estratégias. A estratégia deve ser equacionada sempre num horizonte temporal razoável atendendo os objectivos e fins, se entendida estratégia como meios ou métodos aplicados para se alcançar um determinado resultado. A estratégia deve ser pensada antes de ser implementada, pois há que ter em conta as condições (eminentes e emergentes) bem como o ambiente real (oportunidades e ameaças).

\section{A Inteligência}

$\mathrm{O}$ intelecto se divide em dois segmentos: Segmento da Inteligência: Produção de Conhecimento (medida ofensiva), e o Segmento da Contra-Inteligência: Protecção do Conhecimento (medida defensiva). Esses conceitos, embora estivesse intimamente relacionados com a vida militar (donde são oriundos), hoje aplicam-se na vida civil e muito especificamente na governação, na gestão ou ainda na administração. Assim, a inteligência, a nível estratégico, está associada à obtenção, análise, interpretação e disseminação de conhecimentos ou informações orientadas para a projecção e ante- visão do futuro. De Acordo com Almeida Neto (2009), ${ }^{3}$ inteligência é a actividade permanente e especializada de obtenção de informação, dados, produção e difusão de conhecimento, a fim de assessorar o processo de tomada de decisão. Já a contra-inteligência, em sentido amplo, abrange a prevenção, identificação e neutralização de ameaças (internas e externas). A aplicação destes conceitos, impõe a utilização de metodologia e de técnicas que permitam afastar a prática de acções meramente intuitivas e a adopção de procedimentos científicos com indução e orientação racional. A metodologia utilizada é complementada pela técnica de avaliação futura (eventos actuais com implicações ou tendências no futuro - caracter estratégico/Inteligente), mas também técnicas de avaliação corrente (eventos futuros com implicações hoje - caracter visionário /Contra-Inteligência). Tanto a Inteligência e Contra-Inteligência são complementares. A diferença fundamental entre Inteligência e Contra-Inteligência está em suas finalidades. A Inteligência é caracteristicamente proactiva, ou seja, antecipa factos, visando obter resultados, a partir da análise, interpretação e aplicação do conhecimento. A Inteligência, em nível estratégico, é o exercício permanente de acções direccionadas à obtenção de dados e à avaliação de situações relativas a situações que venham impedir ou a dificultar a conquista ou a manutenção das metas definidas. Estratégia sem inteligência significa caminhar sem direcção. Nesse caso há que prever os eventos futuros e procurar responder quanto antes (hoje). Como técnicas de contra-inteligência podemos evidenciar: 
- O diagnóstico da situação, tendo como finalidade o aprimoramento da aç̧ão estratégica ou ainda o levantamento de hipóteses ou factores de risco (significância probabilística). Centra atenção no conhecimento do ponto de situação antes de induzir qualquer acção. Implica um levantamento dos factores de causalidade, de modo a dar resposta aos problemas identificados (eminentes ou emergentes).

- Análise de previsibilidade (tendências), que é orientada para aç̧ões futuras associadas a oportunidade e ameaças, visando identificar e mitigar os factores de risco e incerteza. Procura eliminar ou estancar situações críticas futuras antes que elas aconteçam. É um bom instrumento para a identificação e selecção das tácticas que vão apoiar a estratégia.

- Análise de implicações que atende a identificação de possíveis consequências resultante de um evento. Os líderes devem analisar as consequências decorrentes das suas decisões antes de anunciarem a decisão, pois pode daí advir implicações positivas ou negativas.

\section{A Contra-Inteligência}

A Contra-Inteligência, ao contrário, é reactiva e antecipativa preventiva e visa manter o domínio da informação considerada chave na gestão. Não obstante, esse carácter defensivo da Contra-Inteligência, os métodos de acção e as suas operações são essencialmente ofensivos. A Inteligência é reconhecida como factor indispensável de assessoria na estrutura administrativa do Estado. A Contra-Inteligência é uma função de controlo estratégico vital para o sucesso das organizações. A Contra-Inteligência é uma abordagem que o Estado pode usar para ver e medir as expectativas dos funcionários, ou seja, para impedir ou prevenir os efeitos colaterais resultantes dos processos reformistas. É importante admitir que a qualidade do serviço público está associado a satisfação material e imaterial do funcionário, e como tal, a plenitude somente é alcançada quando os benefícios da reforma têm uma tangência na vida profissional mas de igual modo na vida social dos funcionários. Desde logo, se sabe onde se estamos e para onde se quer caminhar, dificilmente se tem uma direcção certa, pois todos caminhos passam a servir. A contra-inteligência implica trabalhar com as mentes dos funcionários com vista a induzir a mudança de atitudes e comportamentos, pelo que é vista como ferramenta vital para a análise e interpretação de factores objectivos e subjectivos. No quadro da reforma governativa (realinhamento estratégico), é importante que os líderes se orientem pela faceta centrada na valorização e na aplicação crescente das ferramentas da contra-inteligência de modo a fazerem face o processo de mudanças. Como técnicas da contra-inteligência pode-se evidenciar:

- A análise multidimensional, $\left(360^{\circ}\right)$ da causa-efeito que assume a perspectiva regressiva, tendo como fundamento a identificação de factores de causalidade na vertente múltipla e de igual modo identificar os múltiplos efeitos decorrentes. É uma ferramenta centra- 
da na mitigação dos efeitos, mas com o foco na identificação das causas das causas (multi-causalidade). Um aspecto importante multi-causalidade (as causas das causas). Por exemplo, a gripe pode resultar do esfriamento (causa), que por sua vez resulta da falta de agasalho (causa da causa), e como tal, para combater a gripe não basta eliminar o esfriamento, mas de igual modo estancar a origem da origem).

- A análise antecipativa, que atende à identificação de cenários futuros e equacionamento das condições necessárias para satisfazer o futuro hoje. Trata-se de um termo de desconto (na linguagem financeira), orientado para o valor presente de eventos futuros. Nesse caso queremos saber o que significa uma decisão futura no dia de hoje. Os líderes visionários aplicam essa técnica para trazer os desafios futuros e equacionar a acção a tomar no dia de hoje. Por exemplo, os movimentos revolucionários que pretendiam independência em África (futuro), tomaram como acção (presente) a guerra de libertação.

\section{Armadilha estratégica}

A inteligência visionária se socorre por um conjunto de instrumentos analíticos de suporte, com uma valência táctica-operacional - gestão de contingências e mitigação do efeito risco. Consubstancia-se na indicação de propósitos antagónicos ao que de facto se pretende. Na inteligência estratégica, a acção estratégica é equacionada numa pers- pectiva de resultados de longo, conjugados com a identificação e indução oportunidades e riscos. Na inteligência estratégica visionária, o fim é omisso (latente), e evidencia-se a acção (patente). Já a armadilha estratégica é equacionada numa perspectiva tanto de longo prazo, como de curto prazo. Diz respeito à posição ou à predisposição para fazer face a quaisquer eventualidades a favor ou a desfavor. Esse conceito cuida de estabelecer as bases para induzir ou neutralizar as estratégias e respectivas tácticas. A armadilha estratégica não olha apara resultados imediatos, mas mediatos, o que significa que é equacionada numa vertente ao longo do tempo.

O conceito de inteligência estratégica é diferente do conceito de armadilha estratégica, no entanto, a inteligência Estratégica e a Armadilha Estratégica, são dois lados da mesma moeda. O objectivo central é a necessidade de assegurar a vitória, ou ainda para contrapor potenciais factores de risco que possam inviabilizar a estratégia. $\mathrm{O}$ certo é que se pode levar tempo para "caçar" ou "ser caçado", no entanto, a armadilha estratégica tem como finalidade favorecer a parte que promove. Um exemplo comum de armadilha estratégica tem a ver com a contra-informação em períodos de campanha eleitoral, ou ainda a difamação. Um exemplo comum de inteligência estratégica visionária tem a ver com a acção governativa, em que os dirigentes ao longo do tempo vão fazendo campanha, mostrado as suas boas obras, e quando chega o momento eleitoral, a vitória é certa. - Acção ofensiva. A armadilha é acompanhada por aç̧ões de carácter simulador para desviar a atenção, e deixar transparecer que se está tratando de um 
assunto enquanto por detrás há objectivos omissos (obscuros). Em contra-posição, os líderes devem estar preparados para fazer face a quaisquer armadilhas.

Isso exige acção de inteligência e de contra-inteligência, ou seja, exige a capacidade intelectual de conjugar os factores conhecidos e não conhecidos, factores a favor (oportunidades) e a desfavor (riscos). Neste caso, tanto a inteligência estratégica como a armadilha estratégica tem como papel, estudar o ambiente e decidir sobre as estratégias de acção e de contra-acção; de avanço e de neutralizar ou eliminar de quaisquer eventualidades; proteger as estratégias com acções tácticas. Procura-se desviar a atenção de terceiros ou como a forma como se usa diferentes estratégias para distrair atenção do adversário. Os estrategas usam de igual modo o carácter inofensivo.

\section{A Inteligência na administração pública}

\section{e governação \\ Excelência estratégica corporativa (EEC)}

A excelência corporativa é orientada para a eficiência das intervenções (qualidade e impacto). Vários são os ensinamentos decorrentes do mundo empresarial aplicáveis em diferentes esferas da acção governamental. Tudo reside na forma como o mundo corporativo equaciona as suas estratégias e a inteligência com que elas são formuladas e implementadas. Entre a excelência e a visão estratégica reside a inteligência visionária. É um paradigma assente na concepção do futuro. A excelência é o reflexo combinado de diferentes abordagens associadas ao fu- turo. Denota uma tendência e preocupação crescente progressão e busca da qualidade e oportunidades no futuro. Centra atenção na dominação do futuro. É uma ferramenta necessária para a formulação de políticas e planos estratégicos, operacionais e tácticos de todas as áreas e níveis da organização. A partir de eventos conhecidos (hoje), a inteligência corporativa centra atenção na elaboração de cenários possíveis e resultados para apoiar os dirigentes no direccionamento das estratégias de forma efectiva - maximizar as oportunidades e minimizar os riscos.

A inteligência corporativa se preocupa com os concorrentes que perigam o futuro e não com concorrentes do produto que está no mercado: concorrência do futuro. As parcerias estratégicas ou fusões é sempre no sentido de trazer a coesão e convergência. Uma característica importante na inteligência é o lado de integrar e influenciar o futuro, e como tal passa a ser um papel chave na gestão (liderança). Por vezes olhamos para a liderança como virada para influencia os liderados, no entanto, na inteligência corporativa, a influência também pode ser orientada para clientes ou Accionistas (hierarquias superiores), nascendo deste modo o efeito de dependência. Muitos de nos passamos a olhar para Colgate como nome do produto, e nos esquecemos que o produto chama-se pasta dentífrica. O mesmo acontece com Omo, que passou a ser não a marca do produto, mas o produto. A inteligência tem, de certa forma, o lado de induzir ou influenciar as situações desejadas de modo a maximizar os proveitos esperados ou a mitigar os riscos associados. Como tal, a inteligência assume como papel principal assessorar a gestão em matérias 
de segurança, mas também em termos de divulgação da informação estratégica (marketing) ou ainda na escolha de parceiros estratégicos. A excelência estratégica corporativa (empresarial) integra os seguintes segmentos: (i) Adequabilidade e Adaptabilidade; (ii) Administração Inteligente; e (iii) Liderança visionária do Mercado Futuro.

\section{Adequabilidade e a adaptabilidade}

A intenção da excelência estratégica no mundo corporativo a de tornar as organizações em líderes do mercado no presente e no futuro. Essa tendência, de dimensão estratégica, chama atenção para a faceta de adequabilidade (ambiente externo) e adaptabilidade (ambiente interno). Um primeiro segmento tem a ver com a conjugação das estratégias através de peças separadas que são integradas em bloco visando satisfazer as necessidades do presente e do futuro, dado o seu caracter inovador - Atendendo a dinâmica do ambiente externo como políticas, concorrência, nível de inovação, etc. (meio envolvente). As organizações vão aperfeiçoando o seu produto para satisfazer a demanda, dando diferentes valências e utilidades que vão ao encontro das necessidades do usuário - Adequabilidade. Um segundo segmento tem a ver com o estabelecimento de condições no seio da organização em termos de capital tangível e intangível como competências, aptidões, etc. (envolvente interno), de modo a estar preparada a organização a fazer face os desafios do mercado - Adaptabilidade.

No processo de adequação e adaptação, a organização enfrenta mudanças internas como resultado da dinâmica externa, e como tal, há uma flexibilidade em termos de tarefas, sendo que a estrutura é variável tendo em conta as mudanças. Aposta-se na criatividade e inovação como factores de sucesso. Atende à inclusão e à integração dos factores de risco (concorrentes) como aliado nos processos de longo prazo. A intenção é criar as bases para fazer face às mudanças do ambiente externo e interno, pelo que, em curto prazo, a preocupação é criar o ambiente favorável, eliminando todas barreiras ou factores de risco e inovando constantemente. A inteligência neste caso explora os mercados do futuro, de forma que o investimento reside na capacidade imaginativa, inovadora e na antecipação. Não basta ter estratégia para dizer que o resultado é certo. Há que ajustá-la ao ambiente (interno e externo) sempre que se mostrar determinante (ajustamento). Há que considerar o nível probabilístico de certeza quanto à eficácia da estratégia. Se o nível de incerteza for de $60 \%$ implica que a eficácia probabilística é de $40 \%$, o que implica agregação de factores contingenciais na mesma proporção para fazer face aos riscos. Na conjugação da inteligência adaptativa, procura-se assegurar que o erro estratégico seja igual a zero e a probabilidade de acertar seja de $100 \%$. Cuida de factores de convergência (a serem aproveitados) e os factores de divergência (a serem eliminados). Cria parcerias integrativas parciais ou absolutas.

\section{Administração inteligente}

A administração inteligente se segmenta na noção de "escolha óptima". Implica que a acção dos administradores é uma escolha assente nos postulados de melhor 
decisão e que leva em linha de conta um conjunto de factores previamente analisados. Traz postulados do papel da Administração na era da globalização, e, com efeito, as tecnologias de informação e de comunicação tendem a ganhar espaço nas diferentes esferas. Procura-se analisar os ganhos decorrentes da indução tecnológica bem como ao papel da informação no processo de tomada de decisão. Trata-se de uma administração baseada em informação disponível em tempo real para consulta, acompanhamento e tomada de decisão - dashboard. Adopta novos modelos de administração que dão ênfase aos aspectos criativos dos colaboradores através de incentivos à sua participação em todos os processos de melhoria das actividades e, de uma maneira geral, no acréscimo da qualidade. Nas organizações inteligentes, os colaboradores pensam conjuntamente para explorar oportunidades, criar produtos e serviços e identificar e resolver problemas.

A administração inteligente trata de conjugar as peças que formam a estratégia em longo prazo. Por outras palavras, não é a estratégia que é vista em longo prazo, mas é a estratégia que se monta ao longo do tempo. A estratégia passa a ser um fim e não um meio. O meio é determinado pela acção, ou seja, a acção estratégica é que irá determinar o sucesso da estratégia, de forma que a acção pode perdurar o tempo que for necessário o importante é que a combinação das acções em longo prazo deve determinar o sucesso. Ou seja, é uma forma holística de ver a conjugação estratégica através de peças separadas que são integradas num processo visando satisfazer às necessidades do futuro. A excelência é o reflexo combinado de diferentes abordagens associadas ao futuro. Denota uma tendência e uma preocupação crescente progressão e busca da qualidade e oportunidades no futuro. Centra atenção na dominação do futuro. Quando todos outros chegarem já se estará dominando o futuro. Entre a excelência e a visão estratégica reside a inteligência visionária. É um paradigma assente na concepção do futuro. Identifica e explora os mercados do futuro, sendo que o investimento reside na capacidade imaginativa, indutora de antecipação. Quando todos outros concorrentes despertam, já se esta liderando o mercado.

\section{Liderança visionária}

A excelência estratégica procura identificar padrões de longo prazo que vão se tornar em factores de liderança das organizações. Alguém podia dizer porquê o Facebook comprou o whatsapp por milhões e milhões de dólares? O Bill Gates, em entrevista dizia não entender as razões que levaram o Facebook a comprar o Whatsapp por um valor tão alto, e se ele não comprou foi exactamente porque estava muito caro. Em síntese, pode-se dizer que se denota aqui a sub-estimação do valor futuro, ou o desconhecimento da contribuição do whatsapp na estratégia de integração do facebook, que conseguiu entender o quão importante era equacionar o projecto na sua estratégia integrativa (o seu puzzle), a atender os desafios do futuro. A estratégia de integração está associada à fusão de projectos separados de modo a corporizar um mega projecto integrado, assente no número total de usuários, uns como seu "universo mercadológico" e ou- 
tros como seus "clientes". É preciso entender que para o Facebook interessa um alto número de usuários pois uns vão ser clientes e outros vão constituir o mercado para os seus clientes. Os líderes de sucesso não procuram somente influenciar as pessoas (concepção tradicional de liderança), mas de igual modo, procuram influenciar o ambiente criam as condições para que a estratégia seja de sucesso (concepção visionária). Isso implica que a frente das necessidades do Homem, esteve sempre patente a necessidade de antever o futuro.

Essa antevisão feita por meio de diferentes técnicas, comparações e obtenção de dados era o embrião da inteligência visionária. Hoje, a NASA pode com precisão dizer a que hora um meteorito vai se cruzar com a terra. Passou assim o conhecimento a ser associado com a inteligência, orientada para uma visão de longo prazo, gerado a partir deste sistema a inteligência estratégica. Os líderes visionários assumem diferentes posições para conseguirem um determinado fim e não se preocupam com o valor presente (hoje), mas com o valor futuro. A compra da whatsapp é uma estratégia operacional para satisfazer a estratégia visionária. Apostam na inovação que atende a diversificação de um único produto ou serviço integrado. Capitalizam o lado oculto da estratégia (omissão estratégica) com objectivo de distrair os concorrentes. O investimento esta directamente associado ao valor do futuro. No fim, procura-se desta conjugação estratégica assegurar a liderança do mercado no futuro.

\section{Excelência Estratégica Governativa(EEG)}

A excelência governativa é orientada para a efectividade das intervenções (efeitos, sustentabilidade e durabilidade). A inteligência estratégica governativa diz respeito à capacidade de agir e interagir com a sociedade; a capacidade e habilidade de induzir acções de impacto (fazer muito com pouco). Diz respeito à função de gerir as necessidades e expectativas do cidadão, no presente e no futuro; ou seja a capacidade e levantamento e solucionamento dos problemas correntes e os problemas futuros (evidentes, emergentes e iminentes). A excelência governativa se assenta nos postulados de maior abrangência e envolvimento da população nos processos governativos. É a área da governação que cuida dos aspectos inerentes a analise das intervenções, seu impacto e participação dos actores na tomada de decisão bem como na implementação das decisões. Tem sido ferramenta comum nos períodos eleitorais, e se evidencia pela sua concepção de engajamento e envolvimento.

Excelência estratégica governativa é uma governação baseada nas massas, no povo e na maioria. Segmenta no seio da sociedade o espirito de unidade, revolucionário e de esperança no futuro. Uma questão crítica na governação Pública tem a ver com a desvalorização dos instrumentos de planeamento, e como tal os servidores públicos não estão ao corrente de quais os desafios que a administração deverá assumir no futuro. A Inteligência, em nível governativo, encontra a sua aplicabilidade no planeamento, na organização, na direcção e no controlo governamental, estando presente em todas as suas 
fases e etapas. A Excelência Estratégica Governativa integra os seguintes segmentos: (i) Governação Matricial; (ii) Gestão Governativa; e (iii) Inteligência Responsiva.

\section{Governação Matricial}

A governação matricial tem a ver com a capacidade do governo interagir com outras forças sociedade na busca de soluções que por si somente o Estado teria custos elevados e num período longo em termos de solucionamento dos problemas. Neste caso, acção governamental é entendida como um conjunto coeso de compromissos programáticos e meios para alcança-los, sendo que o Estado identifica um conjunto de actores a serem envolvidos no solucionamento dos problemas. É uma acção governativa orientada para a busca de parceiros estratégico que possam auxiliar o Estado na provisão de bens e serviços, sem perder o caracter de utilidade pública dos mesmos. Não se trata de assumir compromisso político na provisão de bens e serviços, mas a capacidade de coordenação acções de domínio central ou local, orientadas para a satisfação das necessidades da colectividade.

A governação matricial implica a habilidade do executivo liderar o processo de construção colectiva de uma visão de desenvolvimento e bem-estar, e negociá-la com os diferentes actores ouvidas as suas sensibilidades e inquietações (diálogo social). Uma vez consertada, cabe ao poder político induzir políticas tendentes a materializar os problemas levantados, com base de uma visão mobilizada resultante dos interesses da colectividade. Nesse contexto, a liderança es- tratégica assume um papel vital, de modo a que s acção governativa possa ir ao encontro da ansiedade e dos desejos da população. Implica a capacidade de agir e interagir com os diferentes e mais diversificados segmentos com vista a assegurar o envolvimento de todos os actores do processo de solucionamento dos problemas. A liderança matricial implica conjugação de diferentes técnicas e habilidades, orientadas para a materialização dos objectivos e expectativas da sociedade de forma conjunta. São técnicas de exercício de influência perante uma comunidade; formas de dominação "aceite" pela comunidade. A liderança matricial implica o exercício do poder com base em diferentes abordagens, tendo em conta os factores de natureza intrínseca (interno) e factores de natureza extrínsecas (externos). Um líder matricial deve estar preparado para ser o exemplo na sua acção, actuação e interação.

\section{Gestão governativa}

A gestão governamental se centra na identificação e na indução do rumo para o futuro. Trata de influenciar as pessoas e o ambiente para horizontes futuros (capacidade mobilizadora em torno da acção). Cuida de factores de convergência (a serem aproveitados) e os factores de divergência (a serem eliminados). É uma liderança centrada em pessoas e decorre da abordagem sistémica, em que a questão crítica está associada à forma como o processo integrativo se opera. A inteligência na gestão governativa diz respeito à qualidade do governo, a qualidade das intervenções e qualidade das decisões. Diz-se governo inteligente quando as acções a si 
responsabilizadas são implementadas com maior efectividade a atender os objectivos preconizados. Pode significar de igual modo a capacidade de conceber e implementar políticas. A acção governativa exige liderança cada vez mais inteligente. A inteligência na acção governativa é a capacidade de antecipar os cenários como estratégia de gestão das expectativas. Uma liderança inteligente primeiro, prima pela gestão de expectativas na sua governação e como tal, tem a percepção exacta do que esta na mente das pessoas e faz a gestão do processo governativo atendendo a essa percepção. Um segundo elemento é que os actores têm a consciência na governação de qual vai ser o impacto de uma determinada decisão ou acção mesmo antes da sua efectivação, pois nunca se actua sem que haja envolvimento ou intervenção das bases. A acção governativa é orientada pelo desempenho, e como tal as competências institucionais e pessoais são factores catalisadores para uma boa gestão governativa.

Por fim, um líder estratégico que aplica da gestão governativa, prima pela gestão de sinais (comportamentos e atitudes), e se posiciona em função daquilo que é a mentalidade das pessoas. Atende a inclusão dos actores nos processos de curto prazo e de longo prazo. Cria parcerias integrativas parciais ou absolutas. Uma questão crítica é que, mesmo sem dominar o futuro, assume os riscos. Dai que a preocupação nunca é orientada para as necessidades de hoje, mas para as necessidades futuras. Uma questão crítica na governação Pública tem a ver com a desvalorização dos instrumentos de planeamento, e como tal os servidores públicos não estão ao corrente de quais os desafios que a administração deverá assumir no futuro. A gestão governativa é a mais nova área do conhecimento na esfera da governação. Centra atenção na identificação e execução de programas governativos orientados para a efectividade, assegurada a boa gestão e a eficácia de políticas públicas. A construção do futuro implica agregar visão e estratégias, mas também é um processo inteligente - instrumento de ensaio (reconhecimento). No quadro de orientação estratégica é importante que os serviços públicos se orientem por atendendo a sua Missão por uma Visão e os Valores. Desde logo, se não sabemos onde estamos e para onde queremos caminhar dificilmente podemos ter uma direç̧ão certa, pois todos caminhos passam a servir, no entanto nenhum nos leva para lugar algum.

\section{Inteligência responsiva}

A questão central na inteligência responsiva é conhecer muito bem as necessidades e as expectativas da sociedade, que a acção governativa seja implantada, atendendo à capacidade de resposta às necessidades e que o estilo de liderança tenha correspondência às expectativas que isso leva à aproximação dos governantes dos governados, resultando no auto-solucionamento dos problemas. Digamos que as necessidades da sociedade é ter escolas e como expectativa a da inclusão, então, a acção governativa deve responder a necessidade de escola; e o estilo de governação deve privilegiar o diálogo social, que haverá satisfação da sociedade. É importante ter em conta que quando isso acontece, na verdade há uma relação entre a o estilo 
de governação com as expectativas de tal modo que se as expectativas da sociedade forem animadoras, essa sociedade vai se empenhar muito na identificação de soluções tendentes a resolver os seus próprios problemas, e como resultado, tem-se $a$ resposta dos problemas exactamente no lugar onde surgem os problemas.

A inteligência responsiva é a aptidão mais destacável da esfera política. Equaciona a visão socialmente desejável com diferentes abordagens associadas ao alcance dessa mesma visão (vantagens e desvantagens, oportunidades e ameaças, Expectativas e tendências). Um aspecto distintivo a atender a governação visionária tem a ver com a capacidade de resposta do líder $\left(\right.$ responsivo ${ }^{4}$ ); atende à necessidade de satisfação das necessidades e ao anseio da sociedade. Atende ao facto de que o sucesso do processo governativo depende directamente da capacidade de todos actores (dirigentes, servidores e dos beneficiários), pois as decisões inerentes ao processo de desenvolvimento devem ser equacionadas numa perspectiva conjunta (actores activos e proactivos). Na governação responsiva não basta uma visão (desejo), mas o importante é a capacidade de dar resposta em tempo útil; a capacidade de identificar e materializar as soluções socialmente desejáveis que concorrem para a satisfação das necessidades da colectividade; implica agregar habilidades e competências (comunicação, liderança) orientadas para a identificação de soluções de forma conjunta, por forma a que essas tenham maior sustentabilidade e durabilidade $(\mathrm{O}$ senso de pertença e de propriedade leva a um maior engajamento dos actores na preservação, conservação e manutenção da acção governamental). Trata-se de um modelo advogado no quadro do Desenvolvimento Económico Local (DEL).

Na governação responsiva, a acção é orientada para que esta possa induzir os níveis de satisfação, pelo que a concepção das estratégias devem atender aos desafios do presente e do futuro. Um vectores importante e considerado como fundamental, é que a faceta responsiva esta associada às seguintes premissas: (a) Responsabilização dos diferentes actores; (ii) Consciencialização dos diferentes actores; (iii) mentalização dos diferentes actores. Implica mudança de mentalidade nos diferentes níveis, do lado dos beneficiários e do lado dos actores governamentais, pois a qualidade de resposta dependerá do cometimento e envolvimento de todos actores. Bons exemplos são de lembrar no período logo depois da independência. Os actores governamentais e não governamentais se engajavam conjuntamente na solução de problemas. Toda comunidade participava na limpeza das vias com os seus instrumentos nos seus lugares de residência ao final de semana. Implica isso que esta inteligência possibilita que os recursos que $o$ Estado teria de despender para contratar uma empresa de limpeza, poderão ser aplicados para outros fins.

No quadro do fortalecimento, da interação e do relacionamento entre os governadores e governantes, há que atender a necessidade de acção conjunta. $\mathrm{O}$ governante responsivo não é aquele que tem bons planos, mas aquele que consegue 
aplicar os recursos escassos para responder situações que somente o Estado poderá fazer, deixando para uma resposta conjunta com os actores nas demais que assim se possa fazer (Nos momentos de pico em termos de criminalidade, o patrulhamento comunitário é visto como iniciativa de mérito, envolvendo a própria comunidade). A capacidade responsiva chama atenção para a necessidade de prever os cenários e como tal exige-se que ao lideres que sejam cada vez mais visionários. Líder visionário é aquele que trabalha com contornos pouco nítidos, incertezas e riscos difíceis de serem previstos. Traduz premissas de longo prazo, onde a capacidade de influenciar, motivar e coordenar para propósitos de longo prazo é determinante. Define um conjunto de opções Estratégicas que levam ao desenvolvimento da organização e de seus recursos.

\section{Consideracões finais}

O mundo e a sociedade estão sofrendo mudanças constantes, graças às exigências impostas pelo novo cenário global. A inteligência sistémica empreendedora implica gestão do Conhecimento, organizar as principais políticas, processos e instrumentos de gestão e tecnológicas à luz de uma melhor compreensão dos problemas que a sociedade enfrenta hoje e tendências futuras. Implica processos de geração, identificação, validação, disseminação, compartilhamento, proteção e uso dos conhecimentos estratégicos, para gerar resultados e benefícios para a sociedade. Desse modo, torna-se indispensável a capacidade de abstração e a procura de soluções, face aos problemas complexos, para fazer face as ameaças do presente e incertezas quanto ao futuro.

A inteligência estratégica visionária significa pensar antes de agir; agir com convicção quanto ao resultado, impacto e efeitos; significa uma nova forma de conceber e orientar a administração, gestão e governação em termos de acção e actuação. Valoriza os resultados da acção, no entanto prima pelo impacto e efectividade das intervenções. A liderança visionária serve de plataforma para assegurar engajamento e consciencialização dos actores no processo decisório - acção activa e proactiva na governação. Os líderes nacionalistas em África têm o seu mérito exactamente enraizado na sua capacidade de governação visionária. Empreenderam a luta com um propósito não somente de garantir a independência (fins), mas também equacionaram os riscos associados a este desejo (meios), ou seja, os factores de sucesso e os factores de insucesso.

Um governante visionário se orienta por uma perspectiva de produzir ou induzir resultados numa perspectiva de longo prazo onde o papel de cada um dos actores é determinante. Implica a Constituição da visão de longo prazo assente na valorização dos recursos existentes para o alcance dos objectivos operacionais, tácticos e estratégicos. Deve ter clareza das tendências para, a partir disso, equacionar as acções atendendo a dùvia e o risco. A função estratégica está assente em montar os projectos que vão corporizar a estratégia e nasce assim a lógica de estratégia operacional. Um 
governante visionário é visto como interlocutor das sensibilidades da comunidade; consigo leva a preocupação da sociedade e engaja-se na identificação de soluções bem como na materialização das estratégias tendentes a resolver o problema do povo. Dizia Agostinho Neto "O mais importante é resolver os problemas do povo."

\section{Abstract}

The current world puts us in constant challenges to do more and better. This trend for excellence stems, on the one hand, the institutional image, and on the other hand, in search of better positioning in the segments in which we are operating. The concept of governance, in the case of a social and human concept, has not yet as several other social concepts, a general definition accepted by all researchers or experts in the area. Public governance establishes a set of guiding principles of good action and performance of managers and civil servants in honor of the ultimate end state: the full and continuous satisfices the community's needs. This implies that in addressing public policy, it must take into account the methodology of counter-intelligence with the application of techniques and approaches for efficient and realistic analysis of highly complex problems and more effective government action.

Keywords: Public governance. Strategic governance. Reform governance.

\section{Resumen}

El mundo actual nos pone en constantes desafíos de hacer más y mejor. Esta tendencia a la excelencia deriva, por una parte, la imagen institucional, y por el otro lado, en la búsqueda de un mejor posicionamiento en los segmentos en los que están operando. El concepto de gobernanza, en el caso de un concepto social y humano, aún no como varios otros conceptos sociales, una definición general aceptada por todos los investigadores o expertos en el área. La gobernanza pública establece un conjunto de principios de la buena acción y el desempeño de los administradores y funcionarios públicos en honor al estado último fin rector: los satisfaças completos y continuos necesidades de la comunidad. Esto implica que, al abordar las políticas públicas, debe tener en cuenta la metodología de contra-inteligencia con la aplicación de técnicas y enfoques para el análisis eficaz y realista de los problemas de alta complejidad y de la acción de gobierno más eficaz.

Palabras clave: Gobernanza pública. Gobernanza estratégica. Reforma de la gestión de gobierno.

\section{Notas}

1 Disponível em: <http://kumbukilah.blogspot. com/2009/09/governacao-contexto-conceitos-e. html>. Acesso em: 9 set. 2009.

2 De acordo com a Wikipédia.

3 Neto, Almeida (2009). Inteligência e Contra-Inteligência no Ministério Público. Aspectos práticos e teóricos da actividade como instrumento no combate ao crime organizado e defesa dos direitos fundamentais. Belo Horizonte. Brasil. 
4 A governação responsiva prima pela conjugação de esforços no sentido de atender as demandas sociais. Ė a capacidade de resposta da acção governamental, face as necessidades da comunidade.

\section{Referências}

ALMEIDA NETO, W. R. Inteligência e contra-inteligência no Ministério Público: aspectos práticos e teóricos da atividade como instrumento de eficiência no combate ao crime organizado e na defesa dos direitos fundamentais. Belo Horizonte: Dictum, 2009.

PRESUMIDO, Leandro. Inteligência estratégica na atualidade. Disponível em: <http:/ /lumepa. blogspot.com/2010/07/inteligencia-estrategica-na-atualidade.html>. Acesso em: 7 jul. 2007.

LOPES, Pedro Pereira. Governação: contexto, conceito e indicadores. Kumbukil@h. Revista virtual de Pesquisas e Debates. v. 2, n. 1, 2009. Disponível em: <http://kumbukilah.blogspot.com/2009/09/governacao-contexto-conceitos-e.html>. Acesso em: 9 set. 2009. 